Jurnal Ilmu Ilmu Agribisnis: Journal of Agribusiness Science, 9(2), Mei 2021

\title{
ANALISIS MANAJEMEN RISIKO DAN STRATEGI PEMASARAN AGROINDUSTRI KOPI BUBUK (Studi kasus Agroindustri Kopi Bubuk Cap Gunung Betung)
}

\author{
(Risk Management and Marketing Strategies Agroindustry Ground Coffee: case study in Kopi Bubuk Cap \\ Gunung Betung Agroindustry)
}

Asila Jelita Maharani, Dwi Haryono, Adia Nugraha

Jurusan Agribisnis, Fakultas Pertanian, Universitas Lampung, Jl.Prof.Dr.Soemantri Brojonegoro No. 1, Bandar Lampung, 35145,e-mail : dwi.haryono@fp.unila.ac.id

\begin{abstract}
This study aims to analyze the production performance, risk management and marketing strategies agroindustry Gunung Betung coffee powder in Bandar Lampung City. This research use a case study method in Kopi Bubuk Cap Gunung Betung agroindustry. Data collection was conducted on Desember 2019-Januari 2020. This study uses qualitative and quantitative descriptive method. Production performance was analyze using productivity and capacity. Risk agroindustry use ISO 31000 management standard. Strategies marketing use SWOT analyses. Alternative strategies formulated by SWOT matrix. The shows that performance of Kopi Bubuk Cap Gunung Betung Agroindustry in Bandar Lampung city is consider good, process risk, human resource risk, and incidental risks faced are low, the marketing strategies is increase production volume by maintaining and improving product quality, optimizing the use of business locations close to suppliers to increase production volume, utilizing high consumer demand by providing quality products to obtain high profits.
\end{abstract}

Keywords: agroindustry, ground coffee, marketing strategies, production performance, risk management,

\section{PENDAHULUAN}

Pertanian Indonesia terdiri dari beberapa subsektor, yaitu subsektor tanaman pangan, subsektor peternakan, subsektor perikanan, subsektor perkebunan, dan subsektor kehutanan. Salah satu subsektor pertanian yang memiliki peran penting adalah subsektor perkebunan, karena subsektor ini merupakan salah satu subsektor yang mendukung kegiatan industri dan menghasilkan komoditas ekspor. Beberapa tanaman yang dibudidayakan dalam kegiatan perkebunan, antara lain adalah kakao, kelapa sawit, kelapa, kopi, karet, dan beberapa tanaman tahunan lain. Kopi merupakan salah satu komoditas unggulan subsektor perkebunan di Indonesia, karena memiliki peluang pasar, baik di dalam maupun di luar negeri. Kopi merupakan komoditas tropis utama yang diperdagangkan di seluruh dunia dengan kontribusi setengah dari total ekspor komoditas tropis (Kementerian Pertanian 2016).

Kopi merupakan salah satu komoditi hasil perkebunan yang memiliki nilai ekonomis yang cukup tinggi di antara tanaman perkebunan lainnya dan berperan penting sebagai sumber devisa negara. Kopi tidak hanya berperan penting sebagai sumber devisa, melainkan juga merupakan sumber penghasilan bagi tidak kurang dari satu setengah juta jiwa petani kopi di Indonesia. Keberhasilan agribisnis kopi membutuhkan dukungan semua pihak yang terkait dalam proses produksi, pengolahan dan pemasaran komoditas kopi. Upaya meningkatkan produktivitas dan mutu kopi terus dilakukan sehingga daya saing kopi di Indonesia dapat bersaing di pasar dunia (Rahardjo 2012).

Provinsi Lampung merupakan salah satu daerah penghasil kopi terbesar kedua di Indonesia. Provinsi Lampung dikatakan sebagai salah satu daerah penghasil biji kopi terbesar di Indonesia dengan kualitas yang baik dan telah diakui oleh dunia. Kopi Lampung memiliki ciri khas tersendiri baik dari aroma, tekstur hingga cita rasa yang dihasilkan. Kopi yang berasal dari Lampung sangat identik dengan tekstur yang sangat halus serta beraroma coklat. Jenis kopi paling terkenal dan banyak dihasilkan di Lampung ialah kopi robusta. Pengolahan biji kopi menjadi kopi bubuk dapat menghasilkan nilai ekonomis yang tinggi. Industri kopi bubuk mulai banyak diminati oleh para pengusaha di Provinsi Lampung, sehingga terjadi persaingan dalam merebut pangsa pasar kopi bubuk. 
Menurut Dinas Perindustrian dan Perdagangan Provinsi Lampung (2019), terdapat 60 agroindustri kopi bubuk di Kota Bandar Lampung. Salah satu agroindustri kopi bubuk skala besar yaitu Kopi Bubuk Cap Gunung dengan kapasitas produksi sebesar $1.000 \mathrm{~kg} / \mathrm{bulan}$. Banyaknya jenis kopi bubuk yang masuk ke pasar membuat persaingan menjadi semakin meningkat dan tentu berdampak terhadap volume penjualan serta keuntungan yang akan diperoleh oleh pelaku agroindustri penggilingan biji kopi menjadi kopi bubuk. Produsen agroindustri kopi bubuk perlu memperluas pangsa pasar guna meningkatkan volume penjualan untuk mendapatkan pendapatan keuntungan yang maksimal. Analisis manajemen risiko perlu dilakukan untuk melihat seberapa besar agroindustri Kopi Bubuk Cap Gunung Betung menghadapi risiko dalam menjalankan usahanya. Risiko tersebut dapat mencakup risiko proses, risiko sumber daya manusia, dan risiko insidental.

Semakin banyaknya permintaan terhadap kopi bubuk serta pesaing agroindustri penggilingan biji kopi menjadi kopi bubuk, membuat positioning agroindustri di mata konsumen tidak begitu kuat, sehingga menyebabkan banyak konsumen yang tidak mengenal produk kopi tersebut. Oleh karena itu, perlu dilakukan penelitian mengenai strategi pemasaran agar dapat membantu pelaku agroindustri tersebut dalam memasarkan produknya. Tujuan dari dilaksanakannya penelitian ini adalah menganalisis kinerja produksi agroindustri kopi bubuk, menganalisis manajemen risiko agroindustri kopi bubuk, dan menyusun strategi pemasaran Agroindustri Kopi Bubuk Cap Gunung Betung.

\section{METODE PENELITIAN}

Metode yang digunakan pada penelitian ini adalah studi kasus. Penelitian ini dilaksanakan di Agroindustri Kopi Bubuk Cap Gunung Betung yang terletak di Kelurahan Sumber Agung, Kecamatan Kemiling, Kota Bandar Lampung. Penentuan lokasi penelitian dilakukan secara sengaja (purposive) dengan pertimbangan bahwa Agroindustri Kopi Bubuk Cap Gunung Betung masih aktif melakukan produksi kopi bubuk, menghasilkan kopi bubuk dengan kapasitas yang besar, melaksanakan kegiatan produksi, dan memasarkan produknya setiap hari.

Responden pada penelitian ini yaitu dua orang pemilik Agroindustri Kopi Bubuk Cap Gunung Betung, dua orang konsumen Kopi Bubuk Cap
Gunung Betung, satu orang staff bagian penyuluhan dari Dinas Perindustrian, dan satu orang dosen Agribisnis Universitas Lampung sebagai pakar pemasaran. Penelitian ini menggunakan data primer dan data sekunder sebagai data penunjang. Data primer diperoleh secara langsung dari observasi langsung atau pengamatan dan pencatatan langsung tentang proses produksi seluruh produk dan keadaan di agroindustri Kopi Bubuk Cap Gunung Betung untuk menganalisis kinerja produksi, manajemen risiko agroindustri kopi, dan melakukan wawancara untuk menganalis strategi pemasaran dengan menggunakan kuesioner (daftar pertanyaan) yang telah dipersiapkan sebelumnya. Data sekunder merupakan data pendukung untuk penelitian yang didapatkan dari penelitian terdahulu, penelusuran pustaka, serta laporan dari instansi pemerintahan terkait seperti Dinas Perindustrian dan Perdagangan Provinsi Lampung dan data internal agroindustri Kopi Bubuk Cap Gunung Betung.

Kinerja produksi dilihat dari produktivitas dan kapasitas agroindustri. Produktivitas tenaga kerja dari agroindustri dihitung dari unit yang diproduksi (output) dengan masukan yang digunakan (tenaga kerja). Standar nilai besaran produktivitas tenaga kerja menurut Render dan Heizer (2001) adalah $7,20 \mathrm{~kg} / \mathrm{HOK}$. Produktivitas dirumuskan sebagai berikut.

Produktivitas $=$ Unit yang diproduksi $(\mathrm{kg}) \quad .(1)$ Masukan yang digunakan $\mathrm{HOK}$ )

a. Jika produktivitas $\geq 7,20 \mathrm{~kg} / \mathrm{HOK}$, maka kinerja agroindustri tersebut sudah baik.

b. Jika produktivitas $\leq 7,20 \mathrm{~kg} / \mathrm{HOK}$, maka kinerja agroindustri tersebut kurang baik.

Kapasitas yaitu suatu ukuran yang menyangkut kemampuan dari output dari suatu proses. Kapasitas agroindustri diperoleh dari actual output yaitu output berupa kopi bubuk yang diproduksi dan design capacity yaitu kapasitas maksimal memproduksi kopi bubuk dengan satuan $\mathrm{kg}$. Standar nilai besaran kapasitas agroindustri menurut Render dan Heizer (2001) yaitu 0,50. Kapasitas dirumuskan sebagai berikut.

Capacity Utilization $=$ Actual Ouput Design Capacity

Keterangan:

Actual Ouput = Output yang diproduksi $(\mathrm{kg})$ 
Design Capacity $=$ Kapasitas maksimal produksi $(\mathrm{kg})$

a. Jika kapasitas $\geq 0,50$ atau 50 persen, maka kinerja agroindustri tersebut sudah baik

b. Jika kapasitas $\leq 0,50$ atau 50 persen, maka kinerja agroindustri tersebut kurang baik

Proses manajemen risiko dalam penelitian ini akan dianalisis berdasarkan analisis manajemen risiko ISO 31000: 2009. Proses manajemen risiko ISO 31000: 2009 terdiri dari identifikasi risiko, analisis risiko serta perlakuan terhadap risiko. Risiko yang akan dianalisis adalah risiko proses, risiko sumberdaya dan risiko insidental.

Strategi pemasaran disusun dengan mengidentifikasi faktor-faktor internal dan eksternal yang diperoleh berdasarkan faktor kekuatan, kelemahan, ancaman dan peluang kemudian dimasukkan ke dalam maktriks SWOT. Matriks SWOT menggambarkan secara jelas bagaimana peluang dan ancaman eksternal dapat disesuaikan dengan kekuatan dan kelemahan yang terdapat pada pemasaran perusahaan. Matriks SWOT dapat menghasilkan empat sel kemungkinan alternatif strategi, yaitu strategi kekuatan-peluang (S-O), strategi kelemahanpeluang (W-O), strategi kelemahan-ancaman (WT), dan strategi kekuatan-ancaman (S-T).

\section{HASIL DAN PEMBAHASAN}

\section{Karakteristik Responden}

Agroindustri Kopi Bubuk Cap Gunung Betung dimiliki oleh dua orang pemilik. Pemilik agroindustri berumur 61 tahun dan 25 tahun dengan pendidikan SD dan sarjana. Konsumen yang dipilih adalah dua orang konsumen dengan pembelian skala besar. Konsumen tersebut berumur 38 tahun dan 42 tahun dengan jenjang pendidikan SMA dan sarjana. Responden pakar berumur 57 tahun dan 55 tahun dengan jenjang pendidikan sarjana.

\section{Kinerja Produksi}

\section{1) Produktivitas}

Agroindustri menghasilkan $100 \mathrm{~kg}$ untuk satu kali produksi kopi bubuk. Penggunaan tenaga kerja dalam pembuatan kopi bubuk untuk satu kali produksi yaitu 7,0 HOK. Tenaga kerja terbagi menjadi dua orang penyortir, dua orang penggiling, satu orang pemanggang, dan dua orang pengemas kopi bubuk. Berdasarkan hasil perhitungan, produktivitas antara output terhadap tenaga kerja agroindustri Kopi Bubuk Cap Gunung Betung yaitu $14,29 \mathrm{~kg} / \mathrm{HOK}$. Nilai produktivitas lebih dari standar nilai produktivitas tenaga kerja, maka kinerja agroindustri Kopi Bubuk Cap Gunung Betung berdasarkan produktivitas sudah baik. Produktivitas dalam penelitian ini jauh lebih baik dibanding dengan penelitian Sari, Zakaria, dan Affandi (2015) yaitu produktivitas yang dihasilkan oleh agroindustri emping melinjo di Kota Bandar Lampung adalah sebesar 7,29 kg/HOK.

\section{2) Kapasitas}

Output yang dihasilkan oleh agroindustri Kopi Bubuk Cap Gunung Betung dalam sekali produksi adalah sebesar $100 \mathrm{~kg}$ dan kapasitas maksimum per produksi adalah sebesar $160 \mathrm{~kg}$. Berdasarkan perhitungan didapatkan nilai rata-rata kapasitas agroindustri Kopi Bubuk Cap Gunung Betung sebesar 0,625 atau 62,50 persen. Agroindustri Kopi Bubuk Cap Gunung Betung sudah berproduksi dengan cukup baik, karena nilai kapasitas yang didapat lebih dari standar, yang berarti agroindustri ini mampu memproduksi sesuai kapasitas maksimumnya dengan memanfaatkan penggunaan alat dan tenaga kerja secara efektif dan efisien sesuai dengan kapasitasnya.

\section{Manajemen Risiko ISO 31000:2009}

Manajemen risiko ISO 31000: 2009 menyediakan prinsip, kerangka kerja, dan proses manajemen risiko yang dapat digunakan dalam penerapan manajemen risiko yang efektif. Agroindustri Kopi Bubuk Cap Gunung Betung menggunakan 3 jenis manajemen risiko, yaitu risiko proses, risiko sumber daya manusia, dan risiko insidental.

\section{1) Risiko Proses}

Risiko proses merupakan risiko yang terjadi dari proses kegiatan agroindustri yang tidak efektif dan efisien. Hasil analisis risiko proses pada agroindustri Kopi Bubuk Cap Gunung Betung berdasarkan sudut pandang pemilik agroindustri dapat dilihat pada Tabel 1.

Agroindustri Kopi Bubuk Cap Gunung Betung menghadapi dua jenis risiko proses yaitu risiko dari bukti transaksi dan pencatatan akuntansi. Jenis risiko bukti transaksi terjadi, karena pemilik sudah melakukan pencatatan bukti transaksi, tetapi belum terstruktur dan tersimpan dengan baik. 
Tabel 1. Analisis risiko proses pada Agroindustri Kopi Bubuk Cap Gunung Betung

\begin{tabular}{lcccc}
\hline \multirow{2}{*}{ Jenis risiko proses } & \multicolumn{2}{c}{$\begin{array}{c}\text { Probabilitas } \\
\text { terjadinya risiko }\end{array}$} & \multicolumn{2}{c}{$\begin{array}{c}\text { Dampak yang } \\
\text { Ditimbulkan }\end{array}$} \\
\cline { 2 - 5 } & Skor & Probabilitas & Skor & Dampak \\
\hline $\begin{array}{l}\text { Bukti transaksi } \\
\begin{array}{l}\text { Pencatatan } \\
\text { akuntansi }\end{array}\end{array}$ & 3 & Sedang & 3 & Sedang \\
\hline
\end{tabular}

Pencatatan akuntansi juga merupakan risiko yang terdapat pada agroindustri kopi bubuk, karena tidak memiliki pencatatan akuntansi. Perlakuan risiko proses yang dilakukan oleh pihak agroindustri Kopi Bubuk Cap Gunung Betung yaitu mengurangi terjadinya risiko tersebut dengan menyiapkan pembukuan yang terstruktur. Penelitian ini sejalan dengan penelitian Rianzani, Kasymir, dan Affandi (2018) yaitu pencatatan terkadang tidak dilakukan, sehingga data yang ada tidak menginformasikan momen secara aktual.

\section{2) Risiko Sumberdaya Manusia}

Agroindustri Kopi Bubuk Cap Gunung Betung menghadapi tiga jenis risiko sumber daya manusia. Hasil analisis risiko sumber daya manusia berdasarkan sudut pandang pemilik agroindustri dapat dilihat pada Tabel 2. Budaya organisasi merupakan risiko yang dihadapi oleh agroindustri kopi bubuk. Risiko budaya organisasi yaitu mengabaikan risiko atau cenderung merasa aman dalam menjalankan rutinitas operasional, misalnya mengabaikan pencatatan arus kas harian dan merasa aman apabila terjadinya padam listrik saat melakukan proses produksi. Pencatatan arus kas sangat penting, karena menjadi acuan untuk melihat kondisi bisnis yang tengah dijalankan. Pengabaian risiko dapat sangat merugikan pada saat agroindustri membutuhkan modal, sehingga melakukan pinjaman ke bank, laporan keuangan akan dilihat oleh pihak perbankan. Selain itu, risiko apabila terjadi padam listrik, akan tetapi karyawan belum membeli bahan bakar genset untuk antisipasi padam listrik.

Apabila terjadi mati listrik saat biji kopi sedang dipanggang, maka akan menyebabkan warna biji kopi menjadi belang dan merusak cita rasa kopi. Konflik kepentingan juga merupakan salah satu risiko yang dihadapi agroindustri Kopi Bubuk Cap Gunung Betung. Risiko timbulnya konflik tuntutan jam kerja kurang sepadan dengan imbalan yang diperoleh karyawan, sehingga agroindustri berpotensi kehilangan karyawan tertentu.
Tabel 2. Analisis risiko sumberdaya manusia pada Agroindstri Kopi Bubuk Cap Gunung Betung

\begin{tabular}{lcccc}
\hline \multirow{2}{*}{ Jenis risiko proses } & \multicolumn{2}{c}{$\begin{array}{c}\text { Probabilitas } \\
\text { terjadinya risiko }\end{array}$} & \multicolumn{2}{c}{$\begin{array}{c}\text { Dampak yang } \\
\text { Ditimbulkan }\end{array}$} \\
\cline { 2 - 5 } & Skor & Probabilitas & Skor & Dampak \\
\hline Kompetensi dan & & Sedang & 3 & Sedang \\
keahlian & 3 & Sesar & 4 & Besar \\
$\begin{array}{l}\text { Budaya organisasi } \\
\text { Konflik }\end{array}$ & 4 & Ber & & \\
kepentingan & 3 & Sedang & 3 & Sedang \\
\hline
\end{tabular}

\section{3) Risiko Insidental}

Risiko insidental yang dihadapi oleh Agroindustri Kopi Bubuk Cap Gunung Betung adalah risiko yang disebabkan oleh padamnya listrik, kebakaran, gempa bumi, dan pencurian. Hasil analisis risiko sumber daya manusia berdasarkan sudut pandang pemilik agroindustri dapat dilihat pada Tabel 3 . Risiko insidental yang dihadapi oleh Agroindustri Kopi Bubuk Cap Gunung Betung adalah risiko yang disebabkan oleh padamnya listrik, kebakaran, gempa bumi, dan pencurian. Risiko kebakaran, gempa bumi, dan pencurian merupakan risiko insidental yang memiliki dampak yang sangat besar bagi agroindustri Kopi Bubuk Cap Gunung Betung. Kebakaran, gempa bumi, dan pencurian pernah dialami oleh pihak agroindustri yang menyebabkan kerugian yang cukup besar. Kebakaran pernah terjadi pada tahun 2009 di bagian tempat penggilingan kopi karena konsleting listrik. Cara pihak perusahaan untuk mencegah kebakaran yaitu dengan melakukan pengawasan sebelum dan sesudah kegiatan produksi, serta mengimbau untuk selalu berhati-hati dalam melakukan kegiatan produksi kopi bubuk. Risiko gempa bumi juga merupakan risiko yang dapat terjadi sewaktu-waktu karena Kecamatan Kemiling merupakan daerah rawan gempa. Gempa bumi merupakan bencana alam yang sulit untuk diprediksi. Apabila gempa bumi terjadi, maka pihak agroindustri akan mengalami kerugian.

Tabel 3. Analisis risiko insidental pada Agroindustri Kopi Bubuk Cap Gunung Betung

\begin{tabular}{lcccc}
\hline \multirow{2}{*}{$\begin{array}{c}\text { Jenis risiko } \\
\text { proses }\end{array}$} & \multicolumn{2}{c}{$\begin{array}{c}\text { Probabilitas } \\
\text { terjadinya risiko }\end{array}$} & \multicolumn{2}{c}{$\begin{array}{c}\text { Dampak yang } \\
\text { Ditimbulkan }\end{array}$} \\
\cline { 2 - 5 } & Skor & Probabilitas & Skor & Dampak \\
\hline Listrik & & & & \\
Padam & 4 & Besar & 4 & Besar \\
Kebakaran & 5 & Sangat Besar & 5 & Sangat Besar \\
Gempa & & & & \\
Bumi & 5 & Sangat Besar & 5 & Sangat Besar \\
Pencurian & 5 & Sangat Besar & 5 & Sangat Besar \\
\hline
\end{tabular}


Risiko pencurian mesin, motor, dan uang juga pernah terjadi di agroindustri Kopi Bubuk Cap Gunung Betung pada tahun 2012 sehingga menyebabkan kerugian yang sangat besar. Mesin dan alat merupakan aset yang digunakan untuk melakukan kegiatan produksi. Aset perusahaan memungkinkan risiko pencurian pada agroindustri ini. Risiko pencurian juga sangat merugikan perusahaan, baik kerugian materi, maupun keberlangsungan produksi kopi bubuk. Risiko pencurian juga dihindari dengan cara tidak lupa mengunci tempat produksi kopi bubuk, meletakkan sarana prasarana pada posisi yang aman, dan melakukan pengawasan setiap hari.

\section{Strategi Pemasaran}

Strategi pemasaran disusun untuk mempercepat pemecahan persoalan pemasaran dan membuat keputusan-keputusan yang bersifat strategis. Berdasarkan hasil pengisian kuesioner dan pengamatan secara langsung pada agroindustri Kopi Bubuk Cap Gunung Betung di Sumber Agung, Kemiling, didapatkan beberapa faktor internal dan eksternal.

\section{(1) Faktor Internal}

Analisis lingkungan internal Agroindustri Kopi Bubuk Cap Gunung Betung adalah faktor-faktor lingkungan yang berasal dari dalam agroindustri. Penentuan komponen dan bobot ditentukan berdasarkan hasil analisis, serta dengan melihat kondisi Agroindustri Kopi Bubuk Cap Gunung Betung. Faktor internal dari Agroindustri Kopi Bubuk Cap Gunung Betung, adalah produk, lokasi, promosi, dan penjualan seperti pada Tabel 4.

Penilaian faktor kekuatan yang paling penting adalah bahan baku dan produk yang berkualitas dengan bobot yang diberikan adalah 0,188 dengan nilai rating 4 dengan skor sebesar 0,75 . Bahan baku dan produk yang menghasilkan produk kopi bubuk yang berkualitas akan berpengaruh sangat kuat dalam efisiensi pemasaran Kopi Bubuk Cap Gunung Betung. Kopi Bubuk Cap Gunung Betung telah diakui kualitasnya karena telah lulus gugus kendali mutu tingkat nasional. Selain itu, pada kemasan Kopi Bubuk Cap Gunung Betung sudah terdapat izin dari Dinas Kesehatan, PIRT (Pangan Industri Rumah Tangga), SIUP (Surat Izin Usaha Perdagangan), dan SITU (Surat Izin Tempat Usaha) sehingga konsumen merasa aman ketika mengkonsumsinya. Penelitian ini sejalan dengan penelitian Putri, Sayekti, dan Rosanti (2014) yang mengungkapkan bahwa produk yang berkualitas merupakan komponen kekuatan terbesar bagi budidaya rumput laut di Pulau Pahawang, Kecamatan Punduh Pidada, Kabupaten Pesawaran dengan skor sebesar 1,60.

Penilaian faktor kelemahan yang paling penting terdapat pada promosi secara online belum dilakukan secara berkala dengan bobot 0,104 dan nilai rating 3 , sehingga didapatkan skor yaitu 0,3126. Berdasarkan penilaian faktor kelemahan, perusahaan belum melakukan promosi secara online secara berkala. Pemasaran yang dilakukan oleh perusahaan masih dilakukan secara personal dan tatap muka. Kurangnya pengetahuan dalam penggunaan teknologi dan terbatasnya modal yang dimiliki oleh pemilik agroindustri, menyebabkan pemasaran Kopi Bubuk Cap Gunung Betung menjadi kurang optimal. Penelitian ini sejalan dengan penelitian Ledy, Haryono, dan Situmorang (2019) yaitu Agroindustri Kopi Bubuk Cap Intan belum melakukan kegiatan promosi dengan cara periklanan, dengan alasan kurangnya pengetahuan yang dimiliki pemilik maupun karyawan agroindustri dalam menggunakan teknologi dan keterbatasan modal yang dimiliki.

Tabel 4. Matriks IFE Agroindustri Kopi Bubuk Cap Gunung Betung

\begin{tabular}{llrrrc}
\hline No & \multicolumn{1}{c}{ Faktor Internal } & Bobot & Rating & \multicolumn{1}{l}{ Skor } & Ranking \\
\hline 1 & Bahan baku dan produk berkualitas & 0,188 & 4 & 0,7500 & 1 \\
2 & Lokasi usaha strategis dan dekat dengan pemasok & 0,155 & 4 & 0,6192 & 2 \\
3 & Rutin mengikuti pameran yang diadakan pemerintah dan swasta & 0,155 & 3 & 0,4644 & 3 \\
4 & Penjualan sudah dilakukan secara luas & 0,137 & 3 & 0,4107 & 4 \\
\hline 5 & Hanya ada satu jenis varian produk & 0,086 & 2 & 0,1726 & 3 \\
6 & Lokasi usaha jauh dari beberapa konsumen & 0,104 & 2 & 0,2084 & 2 \\
7 & Promosi secara online belum dilakukan secara berkala & 0,104 & 3 & 0,3126 & 1 \\
8 & Pembukuan dari setiap penjualan yang dilakukan masih belum & & & & \\
& diperhatikan & 0,071 & 2 & 0,1428 & 4 \\
\hline & Total & 1,0000 & 3,0807 & \\
\hline
\end{tabular}


Tabel 5. Matriks EFE agroindustri Kopi Bubuk Cap Gunung Betung

\begin{tabular}{|c|c|c|c|c|c|}
\hline No & Faktor Eksternal & Bobot & Rating & Skor & Ranking \\
\hline 1 & $\begin{array}{l}\text { Kebutuhan dan minat konsumen terhadap } \\
\text { produk tinggi }\end{array}$ & 0,173 & 3 & 0,5181 & 2 \\
\hline 2 & Daya saing produk tinggi & 0,137 & 3 & 0,4107 & 3 \\
\hline 3 & Pemanfaatan teknologi produksi & 0,140 & 4 & 0,5596 & 1 \\
\hline 4 & $\begin{array}{l}\text { Adanya dukungan pemerintah Adanya } \\
\text { dukungan pemerintah terhadap peningkatan } \\
\text { konsumsi kopi bagi masyarakat }\end{array}$ & 0,113 & 3 & 0,3393 & 4 \\
\hline 1 & Sebagian besar konsumen jauh dari lokasi usaha & 0,131 & 2 & 0,2618 & 2 \\
\hline 2 & Terdapat beberapa usaha pesaing sejenis & 0,077 & 2 & 0,1548 & 4 \\
\hline 3 & $\begin{array}{l}\text { Teknologi pemasaran belum dimanfaatkan } \\
\text { secara optimal }\end{array}$ & 0,113 & 3 & 0,3393 & 1 \\
\hline 4 & Kurangnya pengawasan dari pemerintah & 0,116 & 2 & 0,2322 & 3 \\
\hline & Total & 1,0000 & & 2,8158 & \\
\hline
\end{tabular}

\section{(2) Faktor Eksternal}

Analisis lingkungan eksternal Agroindustri Kopi Bubuk Cap Gunung Betung merupakan faktorfaktor lingkungan yang berasal dari luar agroindustri. Faktor eksternal mempengaruhi pilihan, maupun tindakan agroindustri baik secara langsung maupun tidak langsung. Faktor eksternal dari Agroindustri Kopi Bubuk Cap Gunung Betung yaitu konsumen, daya saing, dukungan pemerintah, dan teknologi. Matriks EFE dari Agroindustri Kopi Bubuk Cap Gunung Betung dapat dilihat pada Tabel 5.

Berdasarkan hasil pengevaluasian faktor eksternal pada pemasaran Agroindustri Kopi Bubuk Cap Gunung Betung dengan menggunakan metode wawancara menggunakan kuisioner, didapatkan penilaian terhadap peluang dan ancaman yang terdapat dalam menjalani pemasaran Kopi Bubuk Cap Gunung Betung. Penilaian faktor eksternal peluang dan ancaman dalam pemasaran kopi bubuk yaitu faktor konsumen, pesaing, pemerintah, dan teknologi.

Skor Total IFE

Kuat Rata-rata Lemah

Skor Total EFE $3,0-4,0$ 2,0-2,99 1,0-1,99

Tinggi 3,0-4,0

Sedang 2,0-2,99

Rendah 1,0-1,99

\begin{tabular}{|c|c|c|}
\hline II & II & III \\
\hline IV & V & VI \\
\hline VII & VII & IX \\
\hline
\end{tabular}

Penilaian faktor ancaman yang paling penting yaitu teknologi pemasaran belum dimanfaatkan secara optimal. Bobot yang diperoleh sebesar 0,113 dan nilai rating 3 , sehingga didapatkan skor sebesar 0,3393. Oleh karena itu, teknologi pemasaran sangat penting dalam kegiatan perluasan usaha kopi bubuk. Penelitian ini sejalan dengan penelitian Sari, Hudoyo, dan Nugraha (2015) yang mengungkapkan bahwa komponen perluasan usaha merupakan komponen kelemahan terbesar bagi usaha perdagangan telur eceran di pasar tradisional Kota Bandar Lampung yang berpengaruh terhadap volume penjualan dengan skor sebesar 0,25.

\section{(3) Matriks IE}

Berdasarkan hasil analisis faktor internal menggunakan matriks IFE, diperoleh bobot skor sebesar 3,0807 dan hasil analisis faktor eksternal menggunakan matriks EFE diperoleh bobot skor sebesar 2,8158. Posisi agroindustri ditampilkan dalam Gambar 1.

Pemasaran Kopi Bubuk Cap Gunung Betung berada diposisi sel IV. Strategi yang dapat diterapkan pada sel IV adalah strategi pertumbuhan (growth strategy) melalui strategi integrasi vertikal (vertical integration) dan strategi horizontal (horizontal integration). Keadaan strategi tersebut dapat dicapai oleh agroindustri dengan cara memperkuat jaringan atau hubungan terutama dengan pemasok agar jumlah pasokan bahan baku dapat memenuhi hasil permintaan produk di pasaran.

Gambar 1. Matriks IE Agroindustri Kopi Bubuk Cap Gunung Betung. 


\section{(4) Analisis SWOT}

Strategi pemasaran diperoleh dari penyusunan diagram SWOT kemudian disesuaikan dengan posisi agroindustri yang berada pada sel IV. Berdasarkan proses tersebut, dipilih beberapa strategi alternatif antara lain :

1. Meningkatkan volume produksi dengan mempertahankan dan meningkatkan kualitas produk.

2. Optimalisasi pemanfaatan lokasi usaha yang dekat dengan pemasok untuk meningkatkan volume produksi.

3. Memanfaatkan permintaan konsumen yang tinggi dengan menyediakan produk yang berkualitas untuk memperoleh keuntungan yang tinggi.

4. Melakukan inovasi produk kopi bubuk untuk meningkatkan daya saing pemasaran.

5. Menggunakan internet dalam jual beli produk kopi bubuk, sehingga dapat mengadopsi teknologi baru.

6. Meningkatkan manajemen perusahaan dan melakukan pencatatan dari setiap transaksi.

7. Melakukan promosi dan bekerja sama dengan pemerintah atau distributor lainnya.

8. Optimalisasi teknologi pemasaran untuk penjualan yang lebih luas.

9. Menjaga kualitas produk, agar tetap unggul dalam persaingan.

10. Melakukan pelatihan pembuatan produk berbahan dasar kopi dan pelatihan teknologi pemasaran.

11. Melakukan publikasi dan promosi produk kopi bubuk dengan memanfaatkan pengetahuan dan teknologi.

\section{KESIMPULAN}

Kinerja Agroindustri Kopi Bubuk Cap Gunung Betung secara keseluruhan baik. Risiko yang dihadapi oleh Agroindustri Kopi Bubuk Cap Gunung Betung adalah risiko proses, risiko sumberdaya manusia, dan risiko insidental. Strategi pemasaran Agroindustri Kopi Bubuk Cap Gunung Betung yaitu meningkatkan volume produksi dengan mempertahankan dan meningkatkan kualitas produk, optimalisasi pemanfaatan lokasi usaha yang dekat dengan pemasok untuk meningkatkan volume produksi, memanfaatkan permintaan konsumen yang tinggi dengan menyediakan produk yang berkualitas untuk memperoleh keuntungan yang tinggi.

\section{DAFTAR PUSTAKA}

Dinas Perindustrian dan Perdagangan Kota Bandar Lampung. 2019. Dinas Perindustrian dan Perdagangan Provinsi Lampung. Bandar Lampung.

Kementerian Pertanian. 2016. Outlook Kopi. Pusat Data dan Sistem Informasi Pertanian. Jakarta.

Ledy DS, Haryono D, dan Situmorang S. 2019. Analisis bauran pemasaran (marketing mix) dan strategi pengembangan (studi kasus pada Agroindustri Kopi Bubuk Cap intan di Kota Bandar Lampung). Jurnal Ilmu Ilmu Agribisnis, $\quad 7 \quad$ (1): $\quad$ 52-59. http://jurnal.fp.unila.ac.id/index.php/JIA/articl e/view/3331/2552. [1 Juli 2020]

Putri D, Sayekti WD, dan Rosanti N. 2014. Analisis pendapatan dan strategi pengembangan budidaya rumput laut di Pulau Pahawang Kecamatan Punduh Pidada Kabupaten Pesawaran. Jurnal Ilmu Ilmu Agribisnis, 2 (1): 56-63. http://jurnal.fp. unila.ac.id/index.php/JIA/articl e/view/561. [2 Juni 2020]

Rahardjo P. 2012. Panduan Budidaya dan Pengolahan Kopi Arabika danRobusta. Penebar Swadaya. Jakarta.

Render J dan Heizer B. 2001. Prinsip-prinsip Manajemen Operasi: Operations Management. Salemba Empat. Jakarta.

Rianzani C, Kasymir E, dan Affandi MI. 2018. Strategi pengembangan Usaha Ternak Sapi Perah Kelompok Tani Neang Mukti Di Kecamatan Air Naningan Kabupaten Tanggamus. Jurnal Ilmu Ilmu Agribisnis, 3 (2): 179-186. http://jurnal. fp.unila.ac.id/index.php/JIA/article/view/2784 /2330. [2 Juni 2020]

Sari IRM, Zakaria WA, dan Affandi MI. 2015. Kinerja produksi dan nilai tambah Agroindustri Emping Melinjo di Kota Bandar Lampung. Jurnal Ilmu Ilmu Agribisnis, 3 (1): 18-25. http://jurnal.fp. unila.ac.id/index.php/JIA/article/view/101 3. [2 Juni 2020]

Sari TY, Hudoyo A, dan Nugraha A. 2015. Analisis finansial dan strategi pengembangan usaha perdagangan telur eceran: Studi kasus di Pasar Tradisional Kota Bandar Lampung. Jurnal Ilmu Ilmu Agribisnis, 3 (3): 243-250. http://jurnal.fp.unila.ac.id/index.php/ JIA/article/view/1048. [2 Juni 2020] 